\title{
NEURAL NETWORK BASED SIMULATION OF MICRO CREEPING FIBROUS COMPOSITES SIC/AL6061 FOR PLASTIC BEHAVIOUR
}

\author{
VAHID MONFARED* \\ Young Researchers and Elite Club, Zanjan Branch, \\ Islamic Azad University, Zanjan, Iran
}

[Received 17 November 2016. Accepted 20 March 2017]

\begin{abstract}
The present work presents a new approach based on neural network prediction for simple and fast estimation of the creep plastic behaviour of the short fiber composites. Also, this approach is proposed to reduce the solution procedure. Moreover, as a significant application of the method, shuttles and spaceships, turbine blades and discs are generally subjected to the creep effects. Consequently, analysis of the creep phenomenon is required and vital in different industries. Analysis of the creep behaviour is required for failure, fracture, fatigue, and creep resistance of the optoelectronic/photonic composites, and sensors. One of the main applications of the present work is in designing the composites with optical fibers and devices. At last, a good agreement is seen among the present prediction by neural network approach, finite element method (FEM), and the experimental results.
\end{abstract}

KEY WORDS: Artificial neural networks, creep, metal matrix composites (MMCs).

\section{INTRODUCTION}

Recently, application of the neural networks (NNs) represents a novel approach in various applications. Neural network approach is a promising insight for research in predicting analytical, numerical, and experimental trends and behaviours. Also, it has been become increasingly popular in the recent years. Neural networks (NNs) may often solve the problems much faster compared to other methods with the additional ability to learn. Application of the optical devices and optoelectronic composites is recently growing, because of their applications in different industries.

So, a comprehensive study on the plastic behaviour of the materials is vital and significant, because, the plastic phenomenon like creep in the sensors and optoelectronic systems (devices), and optical fibers can be very dangerous. The creep (plastic deformations) in the mentioned systems may create the serious errors and disturbances in the advanced systems. The increasing application of the optical fibers in

*Corresponding author e-mail: vahid_monfared@alum.sharif.edu, vahid_monfared_57@yahoo.com 
the optoelectronic composites requires a methodical knowledge of their creep characteristics, creep resistances, and deformation mechanisms.

Newly, the creep deformations of the short fiber composites with optical fibers are studied in the scientific societies and various industries. Consequently, creep analysis is more important in the related industries. In a word, the creep phenomenon may be dangerous and undesirable for the sensors and optical devices.

Many researchers have studied the $2^{\text {nd }}$ stage creep behaviour by analytical, experimental, and finite element (FE) methods. Finite element method (FEM) is the one of the physically powerful methods for modelling the creep problems [1-3]. For example, the creep deformation behaviour of the metal-matrix composites has been studied by a continuum mechanics treatment, using finite element techniques by Dragon and Nix [1].

In addition, highly developed analytical shear-lag model, applicable to discontinuous fiber composites has been presented [4-8]. For instance, Cox [4] proposed a stress transfer mechanism in the unidirectional long or short fiber composites, which is known as the shear lag model. Moreover, the creep of dispersion reinforced aluminium based metal matrix composite has been investigated experimentally [9-11]. The creep rupture of a silicon-carbide reinforced aluminium composite was studied by Nieh [9]. The $2^{\text {nd }}$ stage creep analysis of silicon carbide whisker/6061 aluminium composite was experimentally performed by Morimoto et al. [10].

As important application and relation of optics and creep, piezoelectric actuators were studied as embedded elements for the quasi-statically active shape control of spatial optical mirrors, because of their excellent properties [12]. Recently, interesting and applied studies have been carried out on creep behaviour and phenomenon [13-15]. For example, the creep properties of three $\mathrm{Sn}-\mathrm{Zn}$ solder alloys have been investigated, utilizing the impression creep technique, in which, micro structural characteristics were inspected employing a scanning electron microscope [14]. Recently, Isik et al., (2014) presented a formation of an Mo-rich Laves phase during hightemperature exposure and creep of a tempered martensite ferritic steel with $12 \mathrm{wt} . \%$ $\mathrm{Cr}$ and $1 \mathrm{wt} . \%$ Mo [15]. Also, analysis of the creep deformation in non-reinforced regions of creeping short fiber composites has been performed under tensile stress using the virtual fiber method [16]. As a different work, changes in mechanical and physical properties of polyurethane thermoplastic during aging at $70^{\circ} \mathrm{C}$ and $90^{\circ} \mathrm{C}$ have been analyzed [17]. In addition, recently as a different research work, creep tests have been fulfilled at 923 and $973 \mathrm{~K}$ on two heats with different solution annealing conditions [18]. Moreover, in the recent years, various investigations and experimental attempts were carried out to analyze the creep behaviours of the materials [19-24]. For example, Monfared [24] predicted stress behaviour in short fiber composites, under axial tensile stress, based on well-behaved displacement rates in 
the steady state creep, using imaginary fiber technique. Also, an approach was based on polynomial approximation of relative displacement on the contact ellipse. For low computational cost and without any spatial discretization, it gave a good estimation of tangential traction and creep. Also, a regularization of the Kalker linear creep theory was presented [25]. Recently, different research works have been presented for analysis of the material deformations in various references [26,27]. For example, the effect of " $\mathrm{SiC}$ " on the characteristics and properties of "Cu/SiC" composites have been analyzed [26]. In which, it was shown that with increasing the volume fraction and particle sizes of the particulate imposed important effect on the thermal and electrical conductivity of the composites. In addition recently, a researcher has studied the topic of energy and transmissibility in nonlinear viscous base isolators with considering creep phenomenon [28]. Moreover, Chen et al., investigated nonlinear geometric effects in mechanical bistable morphing structures. They classified the conditions for bistability, and extended the large deformation theory of plates and shells [29]. Also, they demonstrated, through both theoretical analysis and table-top experiments, that two dimensionless parameters control bistability.

In present research work, prediction of the creep behaviour is presented, using the neural network method, which can improve the accuracy of the creep behaviour predictions in the fibrous composites, particularly when the functional dependency is nonlinear. It is shown, that the neural network method is simpler and faster than the available methods. The present fast method is user friendly and simple in comparison with the difficult analytical, numerical, and experimental methods. To validate the present method and obtained results, the results of the present neural network and experimental methods are compared with together by experimental data for a creeping metal matrix composite (MMC). Metal matrix composite is selected to validate the obtained results, owing to the inaccessibility to the experimental data of the creeping composites.

Lastly, the obtained results are verified through comparison with the experimental data. In which, a suitable agreement is seen among the obtained and available experimental data.

\section{MATERIAL AND METHOD}

Here, a schematically axisymmetric unit cell is presented as a representative of the full short fiber composite with a fiber with its surrounding matrix as two coaxial cylinders. The mentioned unit cell model is shown in Figs. 1a and b. In addition, a complete fiber-matrix interface is assumed.

In addition, a micromechanical and cylindrical unit cell model is used as a representative of the short fiber composites in the present research, shown in Fig. 1b. Also, two cylindrical coordinate systems are used at the center and at the end of the fiber, 


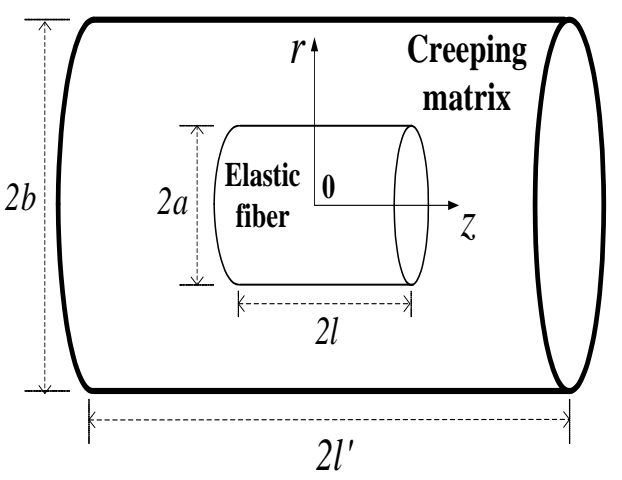

(a)

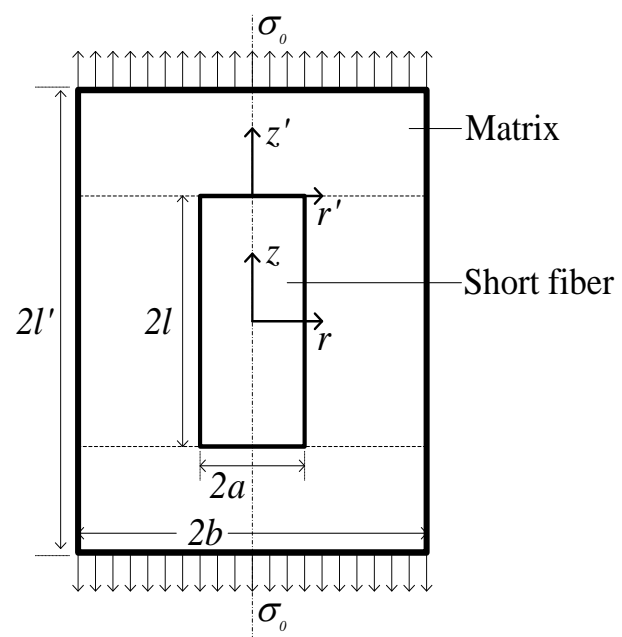

(b)

Fig. 1. (a). The unit cell model scheme; (b). Unit cell model as a composite representative in axisymmetric model under tensile axial stress $\sigma_{0}$.

shown in Figs. 1a, b. The elastic deformation of the fiber is approximately negligible, as compared with the creep deformation of the creeping matrix. That is, the elastic fiber behaviour is similar to the rigid fiber behaviour.

In the present model, it is assumed that a cylindrical fiber with a radius $a$ and a length $2 l$ is inserted in a coaxial cylindrical matrix with an outer radius $b$ and a length $2 l^{\prime}$. The volume fraction and the aspect ratio of the fiber are presented by $f$ and $s=l / a$, respectively. As well, $k=l^{\prime} a / l b$ is considered as a parameter in relation with the geometry of the unit cell. An axial tensile stress, $\sigma_{0}=\sigma_{\text {applied }}$, is uniformly applied at the end faces of the unit cell (at $z= \pm l^{\prime}$ ). The creep behaviour of the matrix is introduced by an exponential law, as the following in Eq. (1):

$$
\dot{\varepsilon}_{e}=A \exp \left(\frac{\sigma_{e}}{B}\right),
$$

at which, $A$ and $B$ are the steady state creep constants of the matrix material and the equivalent stress $\sigma_{e}$ and the equivalent strain rate $\dot{\varepsilon}_{e}$ are given by following formulation:

$$
\begin{aligned}
& \sigma_{e}=\frac{1}{\sqrt{2}} \sqrt{\left(\sigma_{r}-\sigma_{\theta}\right)^{2}+\left(\sigma_{\theta}-\sigma_{z}\right)^{2}+\left(\sigma_{z}-\sigma_{r}\right)^{2}+6 \tau_{r z}^{2}}, \\
& \dot{\varepsilon}_{e}=\frac{\sqrt{2}}{3} \sqrt{\left(\dot{\varepsilon}_{r}-\dot{\varepsilon}_{\theta}\right)^{2}+\left(\dot{\varepsilon}_{\theta}-\dot{\varepsilon}_{z}\right)^{2}+\left(\dot{\varepsilon}_{z}-\dot{\varepsilon}_{r}\right)^{2}+6 \dot{\varepsilon}_{r z}^{2}},
\end{aligned}
$$


in which, the parameters $\dot{\varepsilon}_{r}, \dot{\varepsilon}_{\theta}, \dot{\varepsilon}_{z}$, and $\dot{\varepsilon}_{r z}$ are the strain rate components in the directions, indicated by the subscripts. In addition, the parameters $\sigma_{r}, \sigma_{\theta}, \sigma_{z}$, and $\tau_{r z}$ are the radial, circumferential, axial, and shear stress components, respectively.

Here, the neural network method is introduced for predicting the creep behaviour of the short fiber composites. One of the important advantages of the present model is in fast and simple prediction and analysis of such problems, instead of the time consuming and the complex experimental, analytical, and numerical methods. Additionally, the present approach is very simple for prediction of the composite creep strain rate behaviour. The obtained results are next validated by the experimental data of Morimoto et al., [10].

Fascinatingly, good agreements are found between the present approach and the experimental predictions. A graphical description of a 3-layer feed forward network is shown in Fig. 2.

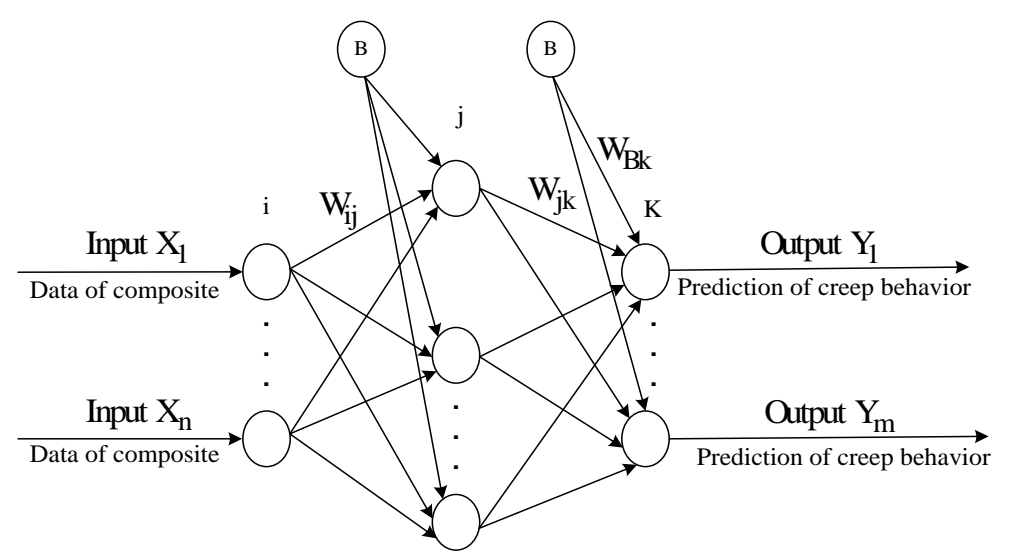

Fig. 2. The graphically presenting the artificial neural network structure and configuration.

Considering that the network consists of $n, p$, and $m$ neurons in input, hidden, and output layers, respectively. The net input $\left(Z_{j}\right)$ to node $j$ in the hidden layer is of the following form:

$$
Z_{j}=\sum_{i=1}^{n} W_{i j} X_{i}+b_{j}, \quad j=1,2, \ldots, p
$$

where, $X_{j}$ is the input of node $j$ of the input layer, $W_{i j}$ is the connection weight in relation with node $i$ of the input layer and node $j$ of the hidden layer, and $b_{j}$ is the bias in relation with node $j$ of the hidden layer. The output $h$ from a neuron is obtained 
by transforming its input, utilizing a appropriate transfer function, as the following:

$$
h_{j}=f\left(\sum_{i=1}^{n} W_{i j} X_{i}+b_{j}\right), \quad j=1,2, \ldots, p .
$$

Also, in the output layer, the net input $Z_{k}$ to node $k$ is of the below form:

$$
Z_{k}=\sum_{j=1}^{p} W_{j k} h_{j}+b_{k}, \quad k=1,2, \ldots, m .
$$

At which, the output $Y_{k}$ of node $k$ of the output layer is written, as the following form:

$$
Y_{k}=g\left(\sum_{j=1}^{p} W_{j k} h_{j}+b_{k}\right), \quad k=1,2, \ldots, m .
$$

Moreover, the error is calculated employing Eq. (8), known as average squared error. Here, $N$ denotes the total number of samples in training set

$$
M S E=\frac{1}{N} \sum_{i=1}^{N}\left(e_{i}\right)^{2}=\frac{1}{N} \sum_{i=1}^{N}\left(t_{i}-a_{i}\right)^{2} .
$$

It should be mentioned, that the artificial neural networks are employed as an interdisciplinary tool in numerous kinds of nonlinear problems. One needs a training algorithm to design a neural network for a certain problem. As a neural networks function, based on samples (patterns), it is required to prepare a set of applied examples, representing the problem in the forms of system inputs and outputs.

Also, to develop a neural network with suitable and good performance, a sufficient quantity of experimental data must be available. During the training and testing sessions, the network architecture, learning algorithm, and the other related parameters of the neural network should also be optimized to the exact problem under analysis.

Once the neural network is adequately optimal, and trained, based on these data, it then becomes possible to create acceptable results when presented with any new input pattern, it has never experienced before.

\section{RESULT AND DISCUSSION}

To verify the present solution method, the $\mathrm{SiC}_{f} / \mathrm{Al}_{m}$ composite is chosen as a case study, and the obtained results are compared with the experimental ones. For the composite used here $\mathrm{SiC}_{f} / \mathrm{Al}_{m}$, the volume fraction of fibers is 0.15 and the fibers have an 


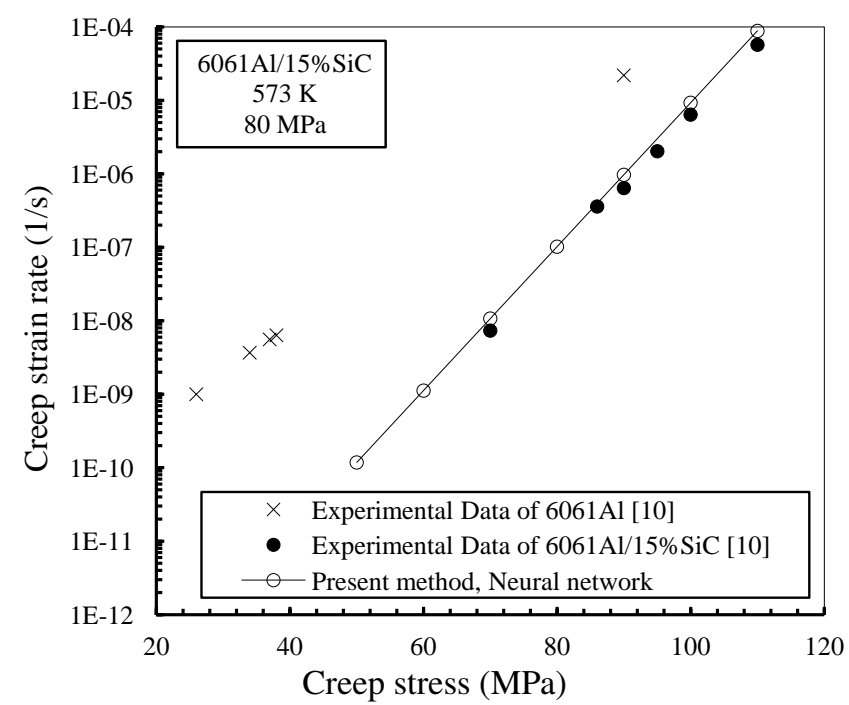

Fig. 3. Comparison of the present and experimental predictions (Morimoto et al. [10]).

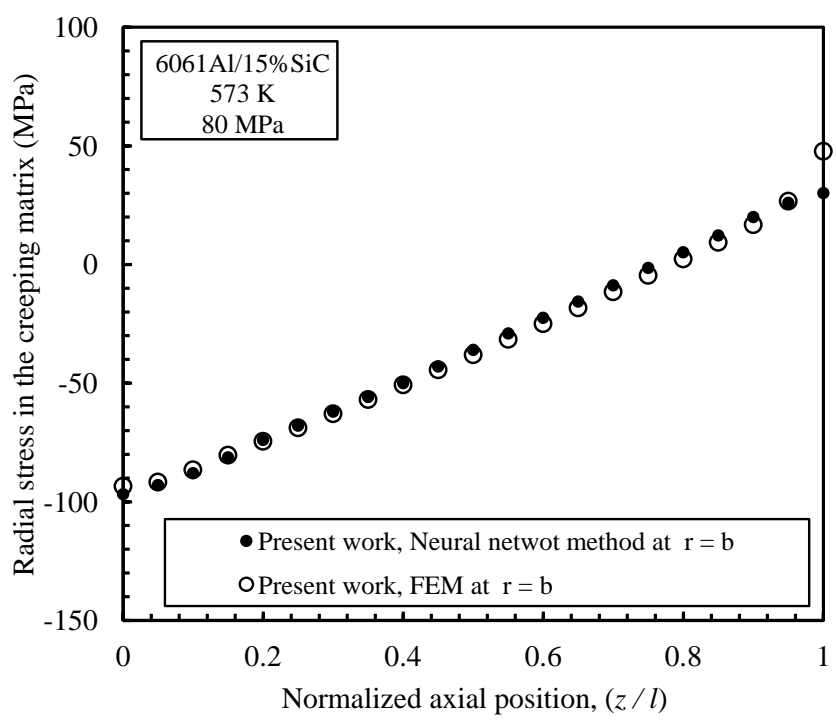

Fig. 4. Comparison of the present method and FEM predictions.

aspect ratio of 7.4 and $k=0.76$, which are in accordance with the suggestions made in [10]. Also, for the creeping the matrix, constants are values of $A=\exp (-24.7)$ and $B=6.47$. As mentioned before, the purpose of the creep analysis by neural network method is in the proper composite design. That is, the creep behaviour must be 


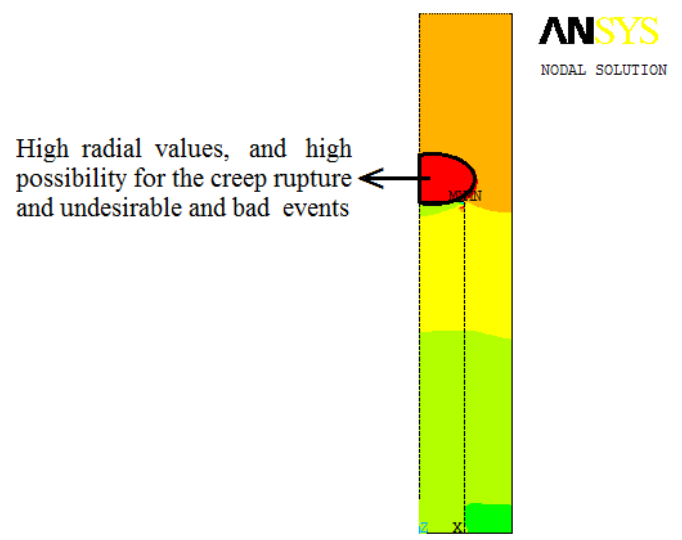

Fig. 5. Presenting the contour nodal solution data of the creep radial stress $(\mathrm{X}$ in FEM $=$ radial direction).

studied to prevent the failure and defect in the creeping short fiber composites. The comparison of the present method and experimental results is presented in Fig. 3. For comparing the results of the present method, because of inaccessibility to the experimental data of the creeping optoelectronic composites, the SiC/6061 Al composite is selected as a case study and also the present method and experimental results are compared together.

Figure 3 shows a high-quality agreement between the present method and experimental results for the second stage creep of the short fiber composite. As well, it is found that the values of the composite creep strain rate increase with increasing the stress values. Based on this behaviour, we can control the composite creep strain rate behaviour, because of the smooth gradients.

Figure 4 presents an excellent agreement between present method and FEM results for the steady state creep of the short fiber composite. Also, it is seen that the values of the radial stress increase with increasing the axial position. Based on this behaviour, we may simply control of the composite radial stress behaviour, because of the uniform and suitable gradients.

The finite element (FEM) analysis of the creep radial stress is graphically shown in Fig. 5. This FEM analysis and solution can be useful to better designing the short fiber composite devices.

In addition, Fig. 5 presents graphically the whole distribution of the creep radial stress, using the contour nodal solution data in the unit cell. This distribution may be valuable for better designing the fibrous composites. Note, that the marked region in Fig. 5 is a critical zone, because undesirable and bad events may happen in the 

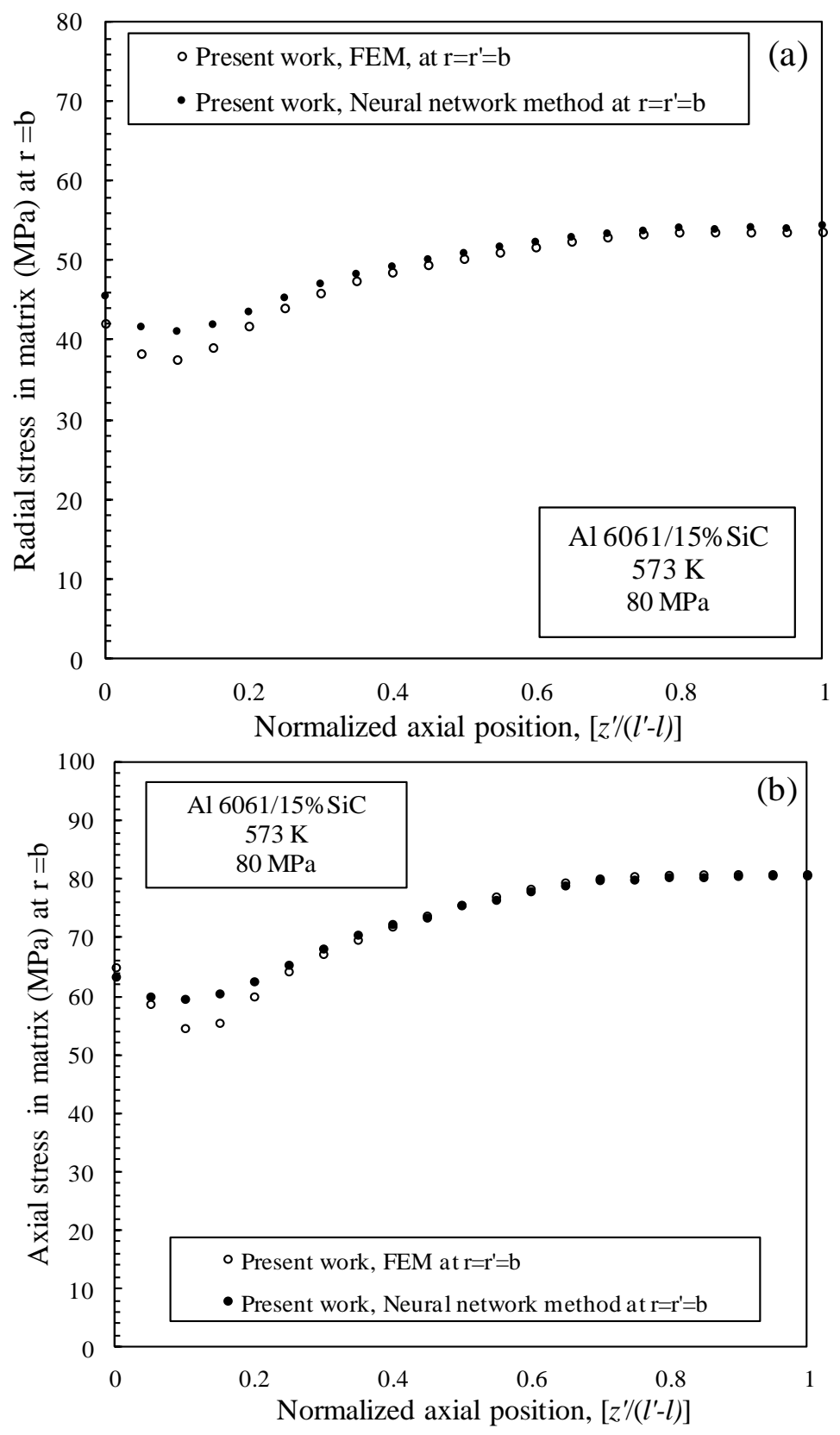

Fig. 6. Stresses in the creeping matrix at $r=r^{\prime}=b, 0 \leq z^{\prime} \leq\left(l^{\prime}-l\right)$ : (a) radial stress. (b) axial stress. 

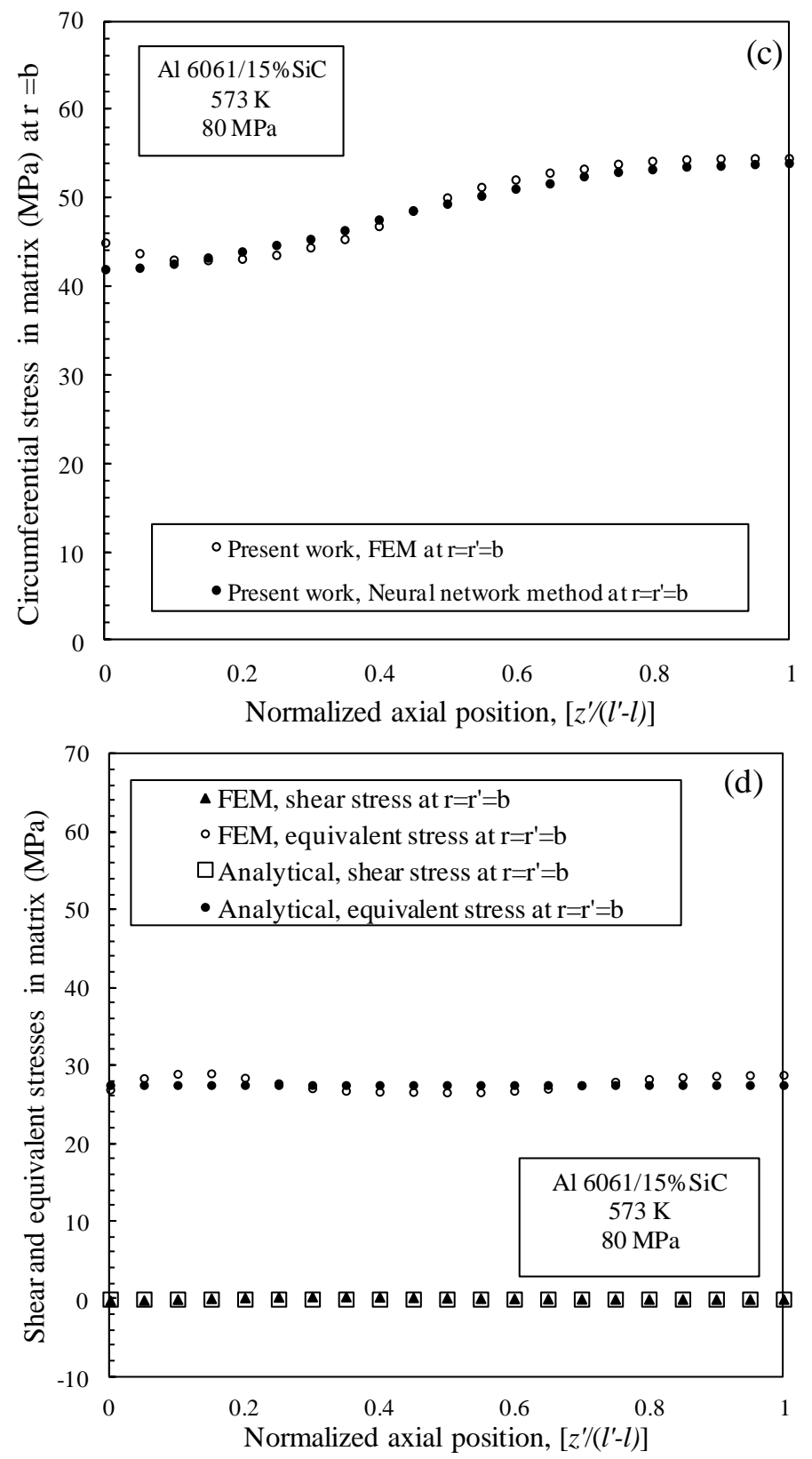

Fig. 6. (continue). Stresses in the creeping matrix at $r=r^{\prime}=b, 0 \leq z^{\prime} \leq\left(l^{\prime}-l\right)$ : (c) circumferential stress; (d) shear and equivalent stresses. 
mentioned region, such as creep rupture.

Figures 6 a-d show the creep behaviour of the matrix in the different regions of the unit cell. In these figures, in all curves presented in Figs. 6 a-d, zero slopes and negligible gradients are also observed at the boundary of the unit cell, which is because of the long distance away from the fiber end and in the proximity to the applied stress in the steady state creep of the short fiber composite. Ascending trends are generally observed in the normal stress values, unlike the trend of the shear and equivalent stress values. These characteristics and behaviours can be beneficial and important for composite design.

The radial and circumferential stress values are approximately the same with a partial difference shown in Figs. 6 a,c. The mentioned same values are because of applying the logical and correct boundary conditions. Equivalent stress is a suitable and important factor to analyze stresses for designing purpose in all regions of the short fiber composites.

\section{SUMMARY AND CONCLUSION}

The present research introduced a novel approach, based on neural network prediction for easy and quick estimation of the creep plastic behaviour of the short fiber composites. The new insight is presented to predict the composite creep radial stress behaviour for the short fiber composites, using neural network method instead of the difficult analytical, numerical, and experimental methods. The possibility of the bad and unwelcome happenings is high in the mentioned region, based on the radial stress values at the fiber end. Finally, good agreements are seen among the present neural network method, FEM, and experimental results. One of the important advantages of the present method is in the application of the approach in place of the other complex methods. Ultimately, we can rely on the present method for predicting the composite creep radial stress values. In addition, the radial stress trend is ascending along with the soft and uniform gradients. So, we can also manage and control the composite creep radial stress behaviour by reason of the smooth gradients. Thus, predicting the creep radial stress behaviour of the short fiber composites is very important for better designing the fibrous composites in the creep of the optoelectronic composite devices and sensors.

\section{REFERENCES}

[1] Dragon, T. L., W. D. NiX. Geometric Factors affecting the Internal Stress Distribution and High Temperature Creep Rate of Discontinuous Fiber Reinforced Metals. Acta. Metall. Mater, 38 (1990), No. 10, 1941-1953.

[2] ISMAR, H., F. SCHRÖTER, F. STREICHER. Inelastic Behaviour of Metal-matrix Composites reinforced with Fibres of Silicon Carbide, Alumina or Carbon: a Finite-element Analysis. Compos. Sci. Technol., 60 (2000), No. 11, 2129-2136. 
[3] KIM, K. J., W. R. YU, M. S. KIM. Anisotropic Creep modelling of coated Textile Membrane, using Finite Element Analysis. Compos. Sci. Technol., 68 (2008), No. 7-8, 1688-1696.

[4] Cox, H. L. The Elasticity and Strength of Paper and other Fibrous Materials. Br. J. Appl. Phys., 3 (1952), 72-79.

[5] Mileiko, S. T. Steady State Creep of a Composite with Short Fibres. J. Mater. Sci., 5 (1970), 254-261.

[6] Fukuda, H., T. W. Chou. An Advanced Shear-lag Model Applicable to Discontinuous Fiber Composites. J. Compos. Mater., 1 (1981), No. 15, 79-91.

[7] MCLEAn, M. Creep Deformation of Metal-matrix Composites. Compos. Sci. Technol., 23 (1985), 37-52.

[8] ZHANG, J. Modelling of the Influence of Fibers on Creep of Fiber reinforced Cementitious Composite. Compos. Sci. Technol., 63 (2003), No. 13, 1877-1884.

[9] NiEH, T. G. Creep Rupture of a Silicon-carbide reinforced Aluminium Composite. Metall. Trans. A., 15 (1984), 139-146.

[10] Morimoto, T., T. Yamaoka, H. Lilholt, M. TAYA. Second Stage Creep of Silicon Carbide Whisker/6061 Aluminium Composite at 573 K. J. Eng. Mater. Technol., 110 (1988), 70-76.

[11] Greasly, A. Creep of Dispersion reinforced Aluminium based Metal Matrix Composite. Mater. Sci. Technol., 11 (1995), 163-166.

[12] Wang, X., V. Pommier-Budinger, A. Reysset, Y. Gourinat. Simultaneous Compensation of Hysteresis and Creep in a Single Piezoelectric Actuator by Openloop Control for Quasi-static Space Active Optics Applications. Control. Eng. Pract., 33 (2014), 48-62.

[13] Griffin, J. The Prediction of Profile Deviations when Creep Feed Grinding Complex Geometrical Features by use of Neural Networks and Genetic Programming with Realtime Simulation. Int. J. Adv. Manufac. Technol., 74 (2014), No. 1-4, 1-16,

[14] Shrestha, T., S. Gollapudi, I. Charit, K. L. Murty. Creep Deformation Behaviour of Sn-Zn Solder Alloys. J. Mater. Sci., 49 (2014), No. 5, 2127-2135.

[15] Isik, M. I., A. Kostka, G. Eggeler. On the Nucleation of Laves Phase Particles during High-temperature Exposure and Creep of Tempered Martensite Ferritic Steels. Acta. Mater., 81 (2014), 230-240.

[16] Monfared, V., S. Daneshmand, J. N. Reddy. Rate Dependent Plastic Deformation Analysis of Short Fiber Composites employing Virtual Fiber Method. J. Comput. Sci., 10 (2015), 26-35.

[17] Boubakri, A., N. Haddar, K. Elleuch, Y. Bienvenu. Influence of Thermal Aging on Tensile and Creep Behaviour of Thermoplastic Polyurethane. Comptes Rendus Mécanique, 339 (2011), No. 10, 666-673.

[18] Ganesan, V., K. Laha, A. K. Bhaduri. Creep Rupture Properties of Indigenously Developed 304HCu Austenitic Stainless Steel. Transactions of the Indian Institute of Metals, 69 (2016), No. 2, 247-251. 
[19] Tapkin, S., A. Çevik, U. UŞara, E. GÜlşan. Rutting Prediction of Asphalt Mixtures modified by Polypropylene Fibers via Repeated Creep Testing by utilising Genetic Programming. Materials Research, 16 (2013), No. 2, 277-292.

[20] Francisco dos Reis Sobrinho, J., L. Oliveira Bueno. Hot Tensile and Creep Rupture Data Extrapolation on 2.25Cr-1Mo Steel using the CDM Penny-kachanov Methodology. Materials Research, 17 (2014), No. 2, 518-526.

[21] Costa Junior, P. R., C. Moura Neto, D. A. Wade. Evaluation of a 7050-TAF Aluminium Alloy submitted to Creep Age Forming. Materials Research, 17 (2014), No. 3, 603-611.

[22] Monfared, V., S. Daneshmand, On the Use of Special Functions for Analyzing the Steady State Creep in Short Fiber Composites Semi-theoretically. Materials Research, 18 (2015), No. 3, 588-594.

[23] Monfared, V. A Displacement based Model to determine the Steady State Creep Strain Rate of Short Fiber Composites. Composites SCIEnCE AND TECHNOlOgY, 107 (2015), 18-28.

[24] Monfared, V. A Micromechanical Creep Model for Stress Analysis of Nonreinforced Regions of Short Fiber Composites using Imaginary Fiber Technique. Mechanics of Materials, 86 (2015), 44-54.

[25] Bovet, C., Jean-Marc Linares, L. Zamponi, E. Mermoz. Multibody Modelling of Non-planar Ball Bearings. Mechanics \& Industry, 14 (2013), 335-345.

[26] Fatoba, O. S., O. Popoola, A. P. I. Popoola. The Effects of Silicon Carbide Reinforcement on the Properties of $\mathrm{Cu} / \mathrm{SiCp}$ Composites. Silicon, 7 (2015), No. 4, 351356.

[27] Morgunov, R. B., O. V. Koplak. Deformation Defects Supporting Quantum Readout of 29 Si Nuclear Spins in Si: P Deformed Crystals. Silicon, 8 (2016), No. 2, 331336.

[28] Markou, A. A., G. D. Manolis. Energy and Transmissibility in Nonlinear Viscous Base Isolators. Journal of Theoretical and Applied Mechanics, 46 (2016), No. 3, 17-34.

[29] Chen, Z., Guo, Q., Majidi, C., Chen, W., Srolovitz, D.J., HaAtaja, M. Nonlinear geometric effects in mechanical bistable morphing structures. Physical Review Letters, 109 (11) (2012), 114302. 